\title{
Combined effect of smoking and occupational exposure to noise on hearing loss in steel factory workers
}

\author{
T Mizoue, T Miyamoto, T Shimizu
}

Occup Environ Med 2003;60:56-59

See end of article for authors' affiliations

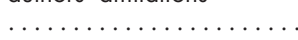

Correspondence to: Dr T Mizove, Department of Preventive Medicine, Faculty of Medical Sciences, Kyushu

University, Japan; mizove@ phealth.med.kyushu-u.ac.jp

Accepted 12 July 2002
Background: Evidence has accumulated concerning the adverse effects of smoking on hearing acuity, but it is not clear whether smoking modifies the association between exposure to noise and hearing loss.

Aims: To examine the synergistic effect of these variables on hearing.

Methods: Data used were derived from periodic health examinations for 4624 steel company workers in Japan and included audiometry testing and information on smoking habits. Occupational exposure to noise was determined based on company records. Logistic regression was used to examine the dose-response association between smoking and hearing loss. The Cochran-Mantel-Haenszel method was used to calculate the prevalence rate ratio (PRR) of hearing loss for each combination of smoking and noise exposure factors, taking non-smokers not exposed to occupational noise as a reference. The interaction between smoking and noise exposure was assessed using a synergistic index, which equals 1 when the joint effect is additive.

Results: Smoking was associated with increased odds of having high frequency hearing loss in a dose-response manner. The PRR for high frequency hearing loss among smokers exposed to occupational noise was $2.56(95 \% \mathrm{Cl} 2.12$ to 3.07$)$, while the PRR for smokers not exposed to noise was $1.57(95 \% \mathrm{Cl} 1.31$ to 1.89$)$ and the PRR for non-smokers exposed to noise was $1.77(95 \% \mathrm{Cl}$ 1.36 to 2.30 ). The synergistic index was 1.16 . Smoking was not associated with low frequency hearing loss.

Conclusions: Smoking may be a risk factor for high frequency hearing loss, and its combined effect on hearing with exposure to occupational noise is additive. ong term exposure to noise at work causes hearing loss. Although countermeasures have successfully reduced noise levels in many industries, noise is still a common occupational hazard, and noise induced hearing loss is one of the major occupational diseases worldwide. ${ }^{12}$ Evidence has accumulated in recent years on the adverse effects of smoking on hearing among the working population ${ }^{3-6}$ as well as among the general population, ${ }^{78}$ while the absence of such association has also been reported. ${ }^{9-13}$ If smoking significantly increases the risk of hearing loss, hearing loss among workers may be treated as a work related impairment consisting, at least in part, of personal risk factors. Compared to office workers, factory workers have an increased risk of hearing loss, because of a high prevalence of smoking and greater exposure to occupational noise. The development of hearing loss may even be accelerated if it were the case that a combination of the two factors had a synergistic effect on hearing, as indicated for some ototoxic chemicals. ${ }^{14}$

Previous studies have mainly focused on the independent association of smoking and hearing, but evidence is limited regarding the combined effects of smoking and noise exposure on hearing. ${ }^{15}$ We therefore investigated the association between smoking and hearing loss in the context of exposure to occupational noise and assessed the interaction between smoking and noise exposure on hearing loss, using data from worker health examinations in a Japanese steel company.

\section{METHODS}

\section{Data source}

Data used were derived from periodic health examinations conducted during fiscal year 1999 on workers in a factory of a major Japanese steel company. In Japan, audiometry tests are provided for all employees, irrespective of noise exposure at work, as part of mandatory health examinations. In addition, governmental guidelines recommend the provision of full band auditory examinations for workers exposed to high levels of noise; the corresponding workplaces, where noise levels are expected to exceed $85 \mathrm{~dB}$, are specified in the guidelines. Following these regulations and guidelines, the present company provides a pure tone air conduction audiometry tests at frequencies of $1000 \mathrm{~Hz}$ and $4000 \mathrm{~Hz}$ for workers not subject to significant noise exposure at work, and additionally at frequencies of $500 \mathrm{~Hz}, 2000 \mathrm{~Hz}$, and $8000 \mathrm{~Hz}$ for those working in noisy environments. Hearing acuity was tested before work of the day by a trained nurse, using an audiometer (DA24, Dana Japan Co. Ltd) in a booth designed specifically for the test. Health related lifestyle information, including smoking data, was obtained at the time of the health examinations, using a self administered questionnaire. Queries on smoking habit included smoking experience (never smoked, quitted, currently smoking) and, for quitters and current smokers, the number of cigarettes smoked per day and the duration of smoking in a year. If multiple examinations were conducted on a given worker during the study period, the results of the first examinations were used. As periodic health examinations are mandatory for all employees, a participation rate of nearly $100 \%$ may be expected for all workers, except for those on extended sick leave during the study period.

\section{Exclusions}

Female subjects were excluded, because of the low percentage of smokers among this group (4\%). A retirement age of 60 is applied to most workers in the company, leaving 5459 male

Abbreviations: $\mathrm{Cl}$, confidence interval; PRR, prevalence rate ratio 
Table 1 Characteristics of the study subjects according to occupational exposure to noise and smoking status

\begin{tabular}{|c|c|c|c|c|}
\hline & \multicolumn{2}{|c|}{ Non-smoker $(n=1693)$} & \multicolumn{2}{|c|}{ Smoker $(n=2931)$} \\
\hline & $\mathrm{n}$ & $\%$ & $\mathrm{n}$ & $\%$ \\
\hline \multicolumn{5}{|c|}{ Occupational noise exposure } \\
\hline No & 1321 & 78 & 1917 & 65 \\
\hline Yes & 372 & 22 & 1014 & 35 \\
\hline \multicolumn{5}{|l|}{ Age (y) } \\
\hline$\leqslant 39$ & 680 & 40 & 907 & 31 \\
\hline $40-49$ & 671 & 40 & 1474 & 50 \\
\hline $50-60$ & 342 & 20 & 550 & 19 \\
\hline
\end{tabular}

subjects aged less than 61 years. Further excluded from this group were individuals without auditory examination results $(\mathrm{n}=225)$, those who provided incomplete information on their smoking histories $(n=3)$, and those who had quit smoking $(\mathrm{n}=646)$, with some overlap among these exclusion criteria. This left 4624 subjects for the present analysis.

\section{Definition of exposure and outcome}

Non-smokers were defined as those who had never smoked in their lifetime. Workplace exposure to noise was determined according to the company records of workers who were selected for special auditory examination for the year. The present company prepares the examination if the subject works in any of the workplaces that are listed in the governmental guidelines for noise control at work. In addition, noise levels at the corresponding work areas are measured twice annually. The A weighted equivalent measurements for the period from April to September 2001 showed that $72 \%$ of 206 work areas had a noise level of $85 \mathrm{~dB}$ or higher; the proportions of work areas with noise levels less than $80 \mathrm{~dB}, 80 \mathrm{~dB}$ to $<85 \mathrm{~dB}, 85 \mathrm{~dB}$ to $<90 \mathrm{~dB}, 90 \mathrm{~dB}$ to $<95$ $\mathrm{dB}$, and $95 \mathrm{~dB}$ or higher were $1.9 \%, 26.2 \%, 41.7 \%, 22.8 \%$, and $7.3 \%$, respectively. These figures may be similar to those for 1999 , since no major changes were made in machinery and factory equipment during the two year period. However, we cannot relate each worker to particular noise levels, because of the high mobility of workers across work areas. No information was obtained concerning exposure to occupational noise more than one year prior to the health examination, the use of personal protective devices, or noise exposure outside the occupational setting. We defined low frequency hearing loss as a hearing threshold greater than $25 \mathrm{~dB}$ at 1000 $\mathrm{Hz}$ and high frequency hearing loss as a threshold greater than $40 \mathrm{~dB}$ at $4000 \mathrm{~Hz}$ (with respect to the ear with poorer test results). Acoustic diseases and injuries that may have had an impact on hearing acuity were not taken into consideration in the analysis, because of a lack of information concerning such factors.

\section{Analysis}

Hearing loss was assessed at frequencies of $1000 \mathrm{~Hz}$ and 4000 $\mathrm{Hz}$, separately. Hearing loss was calculated according to age group ( $<40$ years, $40-49$ years, 50-60 years), occupational noise exposure, and smoking status. The age category was initially defined by 10 year intervals, but the first three categories ( $<20$ years, $20-29$ years, 30 to $<40$ years) were then combined because the corresponding prevalence of study defined hearing loss was no greater than 3\% for both frequency levels. Logistic regression was used to examine the dose-response relation between smoking and hearing loss according to occupational noise exposure, controlling for age as a continuous variable. For this analysis, smoking categories were defined as follows: non-smokers, smokers consuming 1-14 cigarettes per day, smokers consuming 15-24 cigarettes per day, and smokers consuming 25 cigarettes or more per day. The CochranMantel-Haenszel method was used to calculate the prevalence rate ratio (PRR), stratified by the above mentioned age groups, of hearing loss with a $95 \%$ confidence interval (CI) for each combination of smoking and noise exposure factors, taking non-smokers not exposed to occupational noise as a reference group. The interaction between the two factors (A, noise exposure; $\mathrm{B}$, smoking) was assessed using the synergy index $S$, defined as:

$$
S=(R R[A, B]-1) /(R R[A, B \sim]+R R[A \sim, B]-2)
$$

in which $\sim$ denotes the absence of a factor and RR denotes the rate ratio relative to the rate for $(\mathrm{A} \sim, \mathrm{B} \sim) .{ }^{16}$ The ratio $\mathrm{S}$ will be equal to unity under additivity, and will exceed unity if the observed rate ratio for joint exposure exceeds the magnitude predicted based on the sum of the rate ratios. All the above calculations were performed using SAS software. ${ }^{17}$

\section{RESULTS}

Fifty six per cent of male workers in the factory were current smokers and $29 \%$ were working in environments with potentially high levels of noise. Age and employment tenure were highly correlated each other $(r=0.95 ; \mathrm{p}<0.001)$. As table 1 shows, smokers were more likely to be exposed to noise at work, and were somewhat older than non-smokers. As table 2 shows, age was a strong determinant of hearing loss for all combinations of occupational noise exposure and smoking; as age increased, the prevalence of subjects with hearing loss increased markedly. The difference in hearing loss between

Table 2 Prevalence (numerator/denominator) of hearing loss* according to age, occupational exposure to noise, and smoking in 4624 male workers in a steel factory in Japan, 1999

\begin{tabular}{|c|c|c|c|c|}
\hline \multirow{2}{*}{$\begin{array}{l}\text { Occupational noise } \\
\text { exposure }\end{array}$} & \multirow[b]{2}{*}{ Smoking status } & \multicolumn{3}{|l|}{ Age group } \\
\hline & & $\leqslant 39 y$ & $40-49 y$ & $50-60 y$ \\
\hline \multicolumn{5}{|l|}{$1000 \mathrm{~Hz}$} \\
\hline \multirow[t]{2}{*}{ No } & Non-smoker & $0.7(4 / 560)$ & $4.6(23 / 499)$ & $9.2(24 / 262)$ \\
\hline & Smoker & $1.0(6 / 578)$ & $4.1(39 / 954)$ & $12.5(48 / 385)$ \\
\hline \multirow[t]{2}{*}{ Yes } & Non-smoker & $0.8(1 / 120)$ & $6.4(11 / 172)$ & $16.3(13 / 80)$ \\
\hline & Smoker & $2.4(8 / 329)$ & $6.7(35 / 520)$ & $11.5(19 / 165)$ \\
\hline \multicolumn{5}{|l|}{$4000 \mathrm{~Hz}$} \\
\hline \multirow[t]{2}{*}{ No } & Non-smoker & $1.6(9 / 560)$ & 9.4 (47/499) & $25.2(66 / 262)$ \\
\hline & Smoker & $1.4(8 / 578)$ & $18.3(175 / 954)$ & $34.3(132 / 385)$ \\
\hline \multirow[t]{2}{*}{ Yes } & Non-smoker & $0.8(1 / 120)$ & $18.6(32 / 172)$ & $43.8(35 / 80)$ \\
\hline & Smoker & $2.7(9 / 329)$ & $29.8(155 / 520)$ & $52.7(87 / 165)$ \\
\hline
\end{tabular}


Table 3 Age adjusted odds ratio and its $95 \% \mathrm{Cl}$ of hearing loss* according to occupational exposure to noise and smoking in 4624 male workers in a steel factory in Japan, 1999

\begin{tabular}{|c|c|c|c|c|c|c|c|c|c|}
\hline \multirow{3}{*}{$\begin{array}{l}\text { Occupational } \\
\text { noise exposure }\end{array}$} & \multirow{3}{*}{$\begin{array}{l}\text { Non-smoker } \\
\text { (reference) OR }\end{array}$} & \multicolumn{6}{|c|}{ Smoker (cigarettes/day) } & \multicolumn{2}{|c|}{$p$ value for trend } \\
\hline & & \multicolumn{2}{|c|}{$1-14$} & \multicolumn{2}{|c|}{$15-24$} & \multicolumn{2}{|c|}{$25+$} & \multirow{2}{*}{$\begin{array}{l}\text { For all } \\
\text { subjects }\end{array}$} & \multirow{2}{*}{$\begin{array}{l}\text { Among } \\
\text { smokers }\end{array}$} \\
\hline & & $\overline{O R}$ & $95 \% \mathrm{Cl}$ & OR & $95 \% \mathrm{Cl}$ & OR & $95 \% \mathrm{Cl}$ & & \\
\hline & $1321 / 372^{*}$ & \multicolumn{2}{|c|}{$238 / 90$} & \multicolumn{2}{|c|}{$1096 / 598$} & \multicolumn{2}{|c|}{$582 / 326$} & & \\
\hline $1000 \mathrm{~Hz}$ & & & & & & & & & \\
\hline No & 1 & 1.2 & 0.6 to 2.7 & 1.3 & 0.9 to 1.9 & 1.1 & 0.7 to 1.8 & 0.38 & 0.71 \\
\hline Yes & 1 & 0.9 & 0.3 to 2.8 & 1.0 & 0.6 to 1.8 & 1.0 & 0.5 to 1.8 & 0.97 & 0.94 \\
\hline \multicolumn{10}{|l|}{$4000 \mathrm{~Hz}$} \\
\hline No & 1 & 1.8 & 1.1 to 2.9 & 1.9 & 1.4 to 2.4 & 2.1 & 1.6 to 2.9 & $<0.001$ & 0.31 \\
\hline Yes & 1 & 1.2 & 0.6 to 2.6 & 1.6 & 1.1 to 2.2 & 2.6 & 1.8 to 3.9 & $<0.001$ & $<0.01$ \\
\hline
\end{tabular}

smokers and non-smokers was small at $1000 \mathrm{~Hz}$, while it was large at $4000 \mathrm{~Hz}$. Smokers exposed to noise at work showed the highest degree of hearing loss, while non-smokers working without significant noise exposure had the lowest, with individuals subject to either factor (smoking or exposure to noise) situated between these groups. For the age groups of 40-49 years and 50-60 years, hearing loss among smokers exposed to occupational noise can be estimated based on the additive model using the following equation:

$$
P s n=P o+(P s-P o)+(P n-P o)
$$

where Psn is the prevalence of hearing loss at $4000 \mathrm{~Hz}$ for smokers exposed to occupational noise, Ps represents hearing loss among smokers not exposed to noise, and Pn represents hearing loss among non-smokers exposed to noise. As table 3 shows, a dose-response relation was observed between smoking and high frequency hearing loss; odds ratio increased with higher numbers of cigarettes smoked per day. The trend association was more evident among those who had worked in noisy environments. Adjustment of alcohol drinking did not materially change the results (data not shown). Low frequency hearing loss was not associated with smoking. As table 4 shows, the PRR of hearing loss was estimated for each combination of smoking and noise exposure factors, using non-smokers not exposed to occupational noise as a reference group. Smoking and noise exposure each increased PRR for high frequency hearing loss in the absence of the other factor (1.57 and 1.77, respectively), and their combined effects further increased the PRR (2.56). In contrast, an increased PRR of low frequency hearing loss was associated with occupational exposure to noise, but not with smoking. The synergy index S was 0.72 for low frequency hearing loss and 1.16 for high frequency hearing loss.

Table 4 Prevalence rate ratio of hearing loss for the combinations of occupational exposure to noise and smoking among 4624 male workers in a steel factory in Japan, 1999

\begin{tabular}{llllll}
\hline \multirow{2}{*}{$\begin{array}{l}\text { Occupational } \\
\text { noise exposure }\end{array}$} & \multicolumn{2}{l}{ Non-smoker } & & \multicolumn{2}{l}{ Smoker } \\
\cline { 6 - 7 } \cline { 5 - 6 } & PRR* & $95 \% \mathrm{Cl}$ & & PRR & $95 \% \mathrm{Cl}$ \\
\hline $1000 \mathrm{~Hz}$ & 1 & Reference & & 1.14 & 0.82 to 1.58 \\
$\begin{array}{l}\mathrm{No} \\
\text { Yes }\end{array}$ & 1.55 & 0.98 to 2.45 & & 1.50 & 1.05 to 2.15 \\
$\begin{array}{l}4000 \mathrm{~Hz} \\
\mathrm{No}\end{array}$ & 1 & Reference & & 1.57 & 1.31 to 1.89 \\
Yes & 1.77 & 1.36 to 2.30 & & 2.56 & 2.12 to 3.07 \\
\hline
\end{tabular}

PRR, prevalence rate ratio; $\mathrm{Cl}$, confidence interval

*Calculated by the Cochran-Mantel-Haenszel method, stratified by age group

\section{DISCUSSION}

In the present study of workers in a Japanese steel factory, smoking was significantly associated with an increased risk of high frequency hearing loss, and the combined effect of smoking and exposure to occupational noise was comparable to the sum of the independent effects of each factor.

Inconsistent findings have been reported on the association between smoking and hearing loss. ${ }^{3-13}$ The present finding of a dose-response relation at $4000 \mathrm{~Hz}$ indicates that smoking is a risk factor for high frequency hearing loss. Although the mechanism of the adverse effects of smoking on hearing is not clear, it is hypothesised that smoking may damage hair cells though an ischaemic mechanism - that is, by reducing blood flow to the cochlea or by increasing carboxyhaemogolobin. ${ }^{18-21}$ Experimental studies have found nicotinic-like receptors in hair cells, implying direct ototoxic effects of nicotine on hair cell function. ${ }^{22}$ In contrast, we observed no association between smoking and low frequency hearing loss, a finding similar to the previous results by Nakanishi et al, where a close association was determined between smoking and hearing loss at high frequencies, but not at low frequencies. Inner ear cells responsible for high frequency hearing acuity might be easily damaged through ischaemic mechanisms, as they are located at the end of nutrient arteries. In addition, a study showed that high frequency hearing loss was associated with high shear blood viscosity, ${ }^{23}$ which may be caused by smoking. The differential impact of smoking on hearing according to frequency may partly explain the inconsistency of results among studies that linked smoking with average hearing thresholds at a variety of frequencies.

Prince and Matanoski found that the combined effect of smoking and noise was greater than the expected independent effects. ${ }^{15}$ In the present study, however, although smokers working in environments with significant noise had the highest risk of hearing loss at $4000 \mathrm{~Hz}$, the prevalence and the PRR of hearing loss was nearly equal to values estimated based on an additive model. Furthermore, the synergistic index of 1.16 also supports the hypothesis that the joint effects of noise exposure and smoking on hearing are additive. In other words, smoking does not enhance the effect of noise on hearing but instead acts independently.

The advantages of the present study over previous studies are as follows. First, occupational noise exposure for each worker was determined based on company records. Second, the large sample size, together with a high participation rate, allowed us to evaluate the risk of hearing loss among all combinations of smoking and occupational noise exposure factors. However, the present study had the following limitations. First, the cross sectional nature of the study limits the extent of causal inferences that may be drawn from the findings. However, very few workers were relocated as a result of hearing loss; thus, the selection bias arising from such a mechanism should be minimal. Furthermore, the finding of a dose-response relation between 


\section{Main messages}

- Evidence has accumulated about the adverse effects of smoking on hearing acuity, but little is known regarding the combined effects of smoking and exposure to noise.

- Smoking is a risk factor for high frequency hearing loss, irrespective of occupational exposure to noise.

- The joint effects of smoking and exposure to noise on hearing are additive.

smoking and hearing loss indicates that the association is causal. Second, as levels and duration of noise exposure at work vary considerably according to, for example, mobility of a worker across work areas and use of protective devices and equipment, some workers assigned to the specific hearing tests may actually have been exposed to low noise levels. Third, we did not control previous occupational exposure to noise or leisure time exposure to noise, because of a lack of information. Smokers may be more likely to be subject to noise exposure in karaoke bars. However, the risk associated with smoking did not materially change after adjusting for alcohol drinking, a factor more closely related with karaoke, suggesting that the effects of such bias were minimal. Fourth, since information regarding acoustic diseases, head injuries, or drugs with potential impact on hearing acuity was not systematically gathered during the course of routine health examinations, we were unable to exclude some cases of hearing loss attributable to the above factors.

The present results did not show any synergistic effect between smoking and exposure to noise, but this finding does not negate the importance of smoking in terms of protecting workers from hearing loss. As measures reducing worker exposure to noise have been progressively introduced in occupational settings, the relative importance of other aetiological factors (such as smoking) should increase. In fact, among the present subjects in the steel factory, hearing loss at $4000 \mathrm{~Hz}$ among smokers without significant noise exposure was comparable to hearing loss among non-smokers working in noisy environments. In addition, because blue collar workers in general smoke more than office workers and are more likely to be exposed to noise at work, they form a high risk population in terms of hearing impairment. From a public health perspective, multidisciplinary measures minimising exposure to noise and discouraging smoking should be effected for such high risk groups, to help maintain hearing acuity as workers age.

\section{Conclusions}

The present finding indicates, together with previous findings, that smoking is an independent risk factor for high frequency hearing loss. Furthermore, the combined effects of smoking and exposure to noise on hearing may operate in an additive manner. In contrast, smoking was not associated with low frequency hearing loss. Hearing loss among workers can therefore be viewed as a work related and lifestyle related impairment, necessitating a coordinated remedial approach.

\section{Authors' affiliations}

T Mizoue, Department of Clinical Epidemiology, Institute of Industrial Ecological Sciences, University of Occupational and Environmental Health, Japan

\section{Policy implications}

- High frequency hearing loss is an impairment to which both smoking and occupational exposure to noise independently contribute.

- Smoking should be considered when planning measures to prevent hearing loss among workers.

T Miyamoto, Nippon Steel Corporation Kimitsu Works

T Shimizu, Occupational Health Training Center, University of

Occupational and Environmental Health, Japan

\section{REFERENCES}

1 Koh D, Jeyaratnam J. Occupational health in Singapore. Int Arch Occup Environ Health 1998;71:295-301.

2 Uimonen S, Maki-Torkko E, Sorri M. Hearing and occupation. Int J Circumpolar Health 1998;57:156-61.

3 Virokannas H, Anttonen H. Dose-response relationship between smoking and impairment of hearing acuity in workers exposed to noise. Scand Audiol 1995;24:211-16.

4 Fuortes LJ, Tang S, Pomrehn P, et al. Prospective evaluation of associations between hearing sensitivity and selected cardiovascular risk factors. Am J Ind Med 1995;28:275-80.

5 Starck J, Toppila E, Pyykko I. Smoking as a risk factor in sensory neural hearing loss among workers exposed to occupational noise. Acta Otolaryngol 1999;1 19:302-5.

6 Nakanishi N, Okamoto M, Nakamura K, et al. Cigarette smoking and risk for hearing impairment: a longitudinal study in Japanese male office workers. J Occup Environ Med 2000;42: 1045-9.

7 Siegelaub $\mathbf{A B}$, Friedman GD, Kedar A, et al. Hearing loss in adults. Relation to age, sex, exposure to load noise, and cigarette smoking. Arch Environ Health 1974;29:107-9.

8 Cruickshanks KJ, Klein R, Klein BE, et al. Cigarette smoking and hearing loss: the epidemiology of hearing loss study. JAMA 1998:279:1715-19.

9 Friedman GD, Siegeland AB, Seltzer CC. Cigarette smoking and exposure to occupational hazards. Am J Epidemiol 1969;98:175-83.

10 Drettner B. Hedstrand H, Klockhoff I, et al. Cardiovascular risk factors and hearing loss. Acta Otolaryngol 1975;79:366-71.

11 Barone JA, Peters JM, Garabrant DH, et al. Smoking as a risk factor in noise-induced hearing loss. J Occup Med 1987;29:741-5.

12 Brant LJ, Gordon SS, Pearson JD, et al. Risk factors related to age-associated hearing loss in the speech frequencies. J Am Acad Audiol 1996; 7:152-60

13 Karlsmose B, Lauritzen T, Engberg $M$, et al. A five-year longitudinal study of hearing in a Danish rural population aged $31-50$ years. $\mathrm{Br} J$ Audiol 2000;24:47-55

14 Cary R, Clarke S, Delic J. Effects of combined exposure to noise and toxic substances-critical review of the literature. Ann Occup Hyg 1997:41:455-65.

15 Prince M, Matanoski G. Problems in ascertaining the combined effects of exposures: results of an occupational cohort study of the joint effects of noise and smoking on hearing acuity. In: Fechter D, ed. Proceedings of the 4th International Conference on the Combined Effects of Environmental Factors. Baltimore: Johns Hopkins University, 1991:87-91

16 Rothman KJ. Modern epidemiology. Boston/Tronto: Little, Brown and Company, 1986.

17 SAS Institute, Inc. SAS/STAT user's guide, version 6.4. Cary, NC: SAS Institute, Inc., 1989

18 Chung D, Wilson G, Gannon P, et al. Individual susceptibility to noise. In: Hamernik R, Henderson D, Salvi R, eds. New perspectives on noise-induced hearing loss. New York: Raven Press, 1982:51 1-19.

19 Hawkins JE. The role of vasoconstriction in noise-induced hearing loss. Ann Otolaryngol 1971;80:903-13

20 Hultcrantz $\mathbf{E}$, Hillerdahl $M$, Angelborg $C$. Effect of nicotinic acid on cochlear blood flow. Arch Otolaryngol 1982;234:151-5.

21 Fechter L, Thorne P, Nuttall A. Effects of carbon monoxide on cochlear electrophysiology and blood flow. Hear Res 1987;27:37-45.

22 Blanchet C, Erostegui C, Sugasawa M, et al. Acetylcholine-induced potassium current of guinea pig outer hair cells: its dependence on a calsium influx through nicotinic-like receptors. J Neurosci $1996 ; 16: 2574-85$

23 Browning GG, Gatehouse S, Lowe GD. Blood viscosity as a factor in sensorineural hearing impairment. Lancet 1986;1:121-3. 